\title{
Article
}

\section{Post-traumatic stress disorder following childbirth: an update of current issues and recommendations for future research}

McKenzie-Harg, K, Ayers, S, Ford, E, Horsch, A, Jomeen, J, Sawyer, A, Thomson, Gillian and Slade, Pauline

Available at http://clok.uclan.ac.uk/12211/

McKenzie-Harg, K, Ayers, S, Ford, E, Horsch, A, Jomeen, J, Sawyer, A, Thomson, Gillian ORCID: 0000-0003-3392-8182 and Slade, Pauline (2015) Post-traumatic stress disorder following childbirth: an update of current issues and recommendations for future research. Journal of Reproductive \& Infant Psychology, 33 (3). pp. 219-237.

It is advisable to refer to the publisher's version if you intend to cite from the work. http://dx.doi.org/10.1080/02646838.2015.1031646

For more information about UCLan's research in this area go to http://www.uclan.ac.uk/researchgroups/ and search for <name of research Group>.

For information about Research generally at UCLan please go to http://www.uclan.ac.uk/research/

All outputs in CLoK are protected by Intellectual Property Rights law, including Copyright law. Copyright, IPR and Moral Rights for the works on this site are retained by the individual authors and/or other copyright owners. Terms and conditions for use of this material are defined in the policies page. 


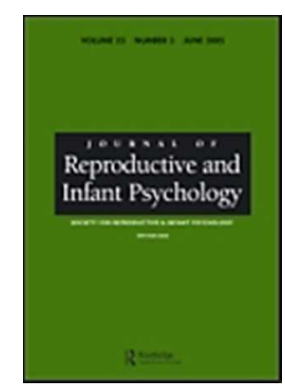

Post-traumatic stress disorder following childbirth: an update of current issues and recommendations for future research

\begin{tabular}{|r|l|}
\hline Journal: & Journal of Reproductive and Infant Psychology \\
\hline Manuscript ID: & Draft \\
\hline Manuscript Type: & Review \\
\hline Keywords: & Childbirth, Pregnancy, Follow-up \\
\hline \multicolumn{2}{l}{} \\
\hline
\end{tabular}

SCHOLARONE ${ }^{m}$

Manuscripts 
1

2

3

4

5

6

7

8

9

10

11

12

13

14

15

16

17

18

19

20

21

22

23

24

25

26

27

28

29

30

31

32

33

34

35

36

37

38

39

40

41

42

43

44

45

46

47

48

49

50

51

52

53

54

55

56

57

58

59

60

Post-traumatic stress disorder following childbirth: an update of current issues and recommendations for future research

This work was supported by the Society for Reproductive and Infant Psychology, Research Developmental Workshop Grant.

URL: http://mc.manuscriptcentral.com/cjri E-mail: support@scholarone.com 
Abstract

Objective: This paper aimed to report the current status of research in the field of post-traumatic stress disorder following childbirth (PTSD FC), and to update the findings of an earlier 2008 paper. Background: A group of international researchers, clinicians and service users met in 2006 to establish the state of clinical and academic knowledge relating to PTSD FC. A paper identified four key areas of research knowledge at that time. Methods: Fourteen clinicians and researchers met in Oxford, UK to update the previously published paper relating to PTSD FC. The first part of the meeting focused on updating the four key areas identified previously, and the second part on discussing new and emerging areas of research within the field. Results: A number of advances have been made in research within the area of PTSD FC. Prevalence is well established within mothers, several intervention studies have been published, and there is growing interest in new areas: staff and pathways; prevention and early intervention; impact on families and children; special populations; and post-traumatic growth. Conclusion: Despite progress, significant gaps remain within the PTSD FC knowledge base. Further research continues to be needed across all areas identified in 2006, and five areas were identified which can be seen as 'new and emerging'. All of these new areas require further extensive research. Relatively little is still known about PTSD FC.

\section{Keywords:}

PTSD; childbirth; review; theory; research

\section{Introduction}

There is now substantial empirical work showing that a proportion of women develop post traumatic stress disorder (PTSD) following childbirth, with potentially wide ranging consequences for them and their families (Fenech \& Thomson, 2014). To date, research has focused on the proportion of women affected, risk factors for the development of PTSD following childbirth, and its impact on women. In contrast, there has been relatively little research into prevention, assessment and intervention. In 2006 an international group of researchers, clinicians and user-group representatives met to discuss the status of knowledge and formulate recommendations for research into PTSD following childbirth. Recommendations were made for research into (1) prevalence and comorbidity of PTSD after birth; (2) screening and treatment; (3) diagnostic and conceptual issues and (4) theoretical issues (Ayers, Joseph, McKenzie-McHarg, Slade \& Wijma, 2008). 
Research and understanding of PTSD following childbirth has increased considerably since that time. In 2014 a small meeting of researchers and clinicians from the UK and Europe was held with the aims of discussing progress in research, and considering key gaps in current understanding (see Appendix for a list of participants). The meeting focused on updating the four primary areas discussed in 2006 and identifying promising areas of developing knowledge.

This paper provides a summary of discussions at this meeting and aims to update our understanding of PTSD following childbirth and recommendations for research. The paper is in two sections. The first considers how research has developed in the areas originally considered in 2006. The second considers emerging areas for research identified as: (1) staff and pathways; (2) prevention and early intervention; (3) impact on families and children; (4) special populations; and (5) post-traumatic growth. As in the previous paper, discussions were based on the knowledge of individuals attending, and the multidisciplinary nature of the group means a variety of views were represented. This paper is not a systematic review but represents the discussions on the day, and an overview of issues raised by participants.

A number of themes arose in most discussions. It was acknowledged that childbirth, when experienced as traumatic, may differ from other potentially traumatic events due to its socially positive connotations, the need to consider at least two individuals at all times (mother and baby), the liminal natural of pregnancy and birth, that the event takes place within the context of formal care, and the potential issues for the mother of caring for a baby who may be a reminder of the trauma. This has implications for labelling, measurement, comparability with other populations with PTSD, and applicability of PTSD research into the context of traumatic birth. Another issue commonly arising was whether traumatic experiences of childbirth should be conceptualised as a diagnostic category or a continuum of distress. These issues are considered further in the sections on conceptual issues and theory.

\section{Section 1: Update on research areas outlined by Ayers et al., 2008}

This section presents the groups' discussions on the four topics considered in the previous paper (Ayers et al, 2008), updating the current knowledge base and identifying ongoing research where applicable. 


\section{Prevalence and Comorbidity}

The 2008 paper identified three issues within this topic: prevalence; course of PTSD; and methodological issues to be considered. The prevalence of PTSD following childbirth has been widely examined and meta-analyses of this research suggest it is $3.1 \%$ in all postnatal women and $15.7 \%$ in high risk groups (Grekin \& O'Hara, 2014). Since 2006, there has been an increase in research examining prevalence in other groups, such as fathers, specific populations (such as those experiencing stillbirth), and staff, all of which provide some evidence that PTSD following childbirth (PTSD FC) can occur within these groups. Because of the relatively smaller numbers of studies that focus on these groups, reported prevalence rates vary and more research is needed. The implications of the new diagnostic criteria in the Diagnostic and Statistical Manual of Mental Disorders (DSM-5, APA, 2013) are unknown at present as all published research thus far has been conducted using DSM-IV criteria.

The natural course of PTSD FC is still poorly understood, and research needs to chart incidence, severity, duration and recovery phases utilising longitudinal methods. Comorbidity with depression is known to be high, with reported rates from 20-75\% (Stramrood et al., 2011; White, Matthey, Boyd \& Barnett, 2006). However, comorbidity with other mental health problems is unknown. Differentiating between PTSD FC and postnatal depression (PND) is not straightforward as several symptoms overlap.

Methodological issues in this area remain largely unchanged. Robust measures are needed, adapted to the perinatal period, to ensure that women are being appropriately identified as having PTSD FC. Research using clinical interviews remains rare and usually reports lower prevalence rates (Grekin \& O'Hara, 2014). There are very few studies looking at long-term outcomes after the first year.

\section{Screening and Treatment}

The 2008 paper considered screening, treatment and impact of PSTD on women and their families. Many of the issues outlined in 2008 remain. Screening for PTSD FC is not common in maternity care, and the disorder remains largely unrecognised outside specialist perinatal and/or maternity services. Research is needed to examine the context and process of screening as well as identifying appropriate tools. For example there are questions around when screening should take place, by 
whom, and what the best method might be of raising staff and patient awareness. The process of screening can raise anxiety and hence it is important to administer screening in an appropriate manner, and ensure that referral routes exist. The course and onset of comorbid PTSD and depression is also unclear, although clinicians in the group suggested PND is usually secondary to PTSD FC. It is also important to consider symptom overlap with comorbid mental health issues, such as depression or generalised anxiety, and how best to assess for these.

Since 2008, a few studies have looked at interventions for women with PTSD FC. These predominantly comprise case studies but suggest that PTSD treatments such as CBT and EMDR are effective (Ayers, McKenzie-McHarg \& Eagle, 2007; Sandstrom, Wiberg, Wikman, Willman \& Hogberg, 2008; Stramrood et al, 2012).

The role of charities, service user groups and advocacy groups has gained prominence in supporting the development of quality services providing input to women and their families. For example, in the UK, the Maternal Mental Health Alliance was set up as an umbrella advocacy group for organisations working within the perinatal period. Their campaign for improved recognition and services was launched in 2014 (see www.everyonesbusiness.org.uk). Internationally, there are calls for maternal mental health to be fully integrated into maternity care (Rahman et al., 2013). These and other initiatives provide an opportunity for PTSD FC to be appropriately recognised.

\section{$\underline{\text { Diagnostic and Conceptual Issues }}$}

The 2008 paper considered whether PTSD FC is the same as PTSD following other events, and whether focus should be broadened to include other forms of distress. Diagnostic issues remain paramount. To date, all published research utilises DSM-IV criteria, which included somatic symptoms common in the postnatal population such as 'difficulty falling or staying asleep', 'difficulty concentrating' and 'hypervigilance'. This has issues for how we conceptualise, diagnose and screen for postnatal PTSD. DSM-5 has changed how PTSD is classified and it is now a 'trauma and stressorrelated disorder' rather than an anxiety disorder. Event criteria have changed, including the removal of the previous criterion A2 which specified that individuals must respond to the traumatic event with intense fear, helplessness or horror. In DSM-5 a cluster of symptoms has been added to include 'negative alterations in cognitions and mood associated with the traumatic event(s)'. Symptoms such as loss 
of interest or participation in significant activities, persistent negative emotional state, and inability to experience positive emotions could also be attributed to depression.

These changes are critical and impact on the prevalence, conceptualisation and diagnosis of PTSD FC. For example, two large studies (UK and Australia) suggest the removal of $A 2$ will increase prevalence rates of PTSD FC because many women perceive a threat of injury or death during birth (Ayers, Harris, Sawyer, Parfitt, \& Ford, 2009; Boorman, Devilly, Gamble, Creedy, \& Fenwick, 2014). Research is therefore needed to examine the implications and utility of DSM-5 criteria in comparison to other diagnostic criteria, such as DSM-IV or ICD-10 (World Health Organisation, 2010).

Another issue is the importance of recognising the impact of sub-threshold symptomatology, particularly when broadening the focus on the full range of distress rather than just diagnosis. Many women may not meet full caseness for a diagnosis of PTSD, but clinically group members reported that this may still negatively impact on their functioning, particularly if they are experiencing symptoms of reexperiencing. Given the potential impact of PTSD on women and their families, intervention remains important even where a diagnosis cannot be given if there is a clear impact on levels of distress or functioning.

\section{Theoretical Issues}

Research in PTSD FC has been predominantly atheoretical, in that it has rarely been explicitly based on theory. Careful consideration of relevant theories can contribute to greater clarity of concepts and understanding of different explanations for PTSD following childbirth. Theories of PTSD, stress, and specifically about PTSD FC are all relevant. Theoretical mechanisms proposed to perpetuate symptoms of PTSD after traumatic events include dysfunctional cognitions (Ehlers \& Clark, 2000), memory processes (Brewin, 2001; Ehlers \& Clark, 2000), and negative social phenomena (Charuvastra \& Cloitre, 2008). Ehlers \& Clark's (2000) theory proposes that PTSD occurs if individuals process the event or its sequelae in a way which produces a sense of current threat, with negative thoughts and cognitions about the event, and a disturbance or block in memory processing (Ehlers \& Clark, 2000). This model has been applied to PTSD FC and found to be a good predictor of PTSD FC symptoms (Ford, Ayers \& Bradley, 2010; Vossbeck-Elsebusch, Freisfeld \& Ehring, 2014). 
Relevant stress theories include those by Lazarus and Folkman (1984), who emphasised the importance of appraisal in stress responses. Stress arises when events are appraised as high threat and coping ability is perceived to be low. Diathesis-stress frameworks account for the interaction between individual vulnerability and events to determine outcome. Specific conceptual frameworks using stress theories for perinatal populations have been proposed. Ayers (Ayers, 2004; Ayers \& Ford, in press) used a diathesis-stress framework to propose a model of vulnerability and risk factors for PTSD following childbirth, and to summarise factors that might be involved in the aetiology of the condition. Slade (2006) provided a detailed conceptual framework which includes predisposing, precipitating, and maintaining factors which relate to internal, external and interactional influences.

Whilst the application of theory is increasing, there is still much to be done to evaluate theoretical frameworks for PTSD FC. Greater application and testing of existing PTSD theories to PTSD FC is needed, including exploration of proposed mediating factors, such as memory processes involved in trauma memories, and how they differ in women with and without PTSD following birth. Research is also needed to extend the theories applied to childbirth. Theories thus far are mainly psychological; however social theories and those from other disciplines may also be relevant. For example, liminality theories, which understand birth as a rite of passage (Kenworthy Teather, 2005; Parratt, 2008) may provide a different perspective.

Research should also examine the role of social bonds within the development of PTSD between the woman, her caregivers, her partner and her infant as well as her family and personal networks and the impact of these. A major role for attachment theory in terms of adult attachment patterns as predisposing vulnerability factor is also emerging (lles et al 2011). Additionally, it would be valuable to see research on high risk subgroups, such as stillbirth, being informed by theoretical frameworks.

\section{Section 2: Important or emerging areas of research in PTSD FC}

Five important or emerging areas of research are focused on here: staff and pathways, prevention and early intervention, impact on families and infant, special populations, and post-traumatic growth.

\section{$\underline{\text { Staff and Care Pathways }}$}

Evidence indicates that one significant cause of a woman's perception of birth as traumatic is the actions/inactions of maternity staff, which can result in care being experienced as dehumanising, disrespectful or uncaring (Elmir, Schmeid, Wilkes \& 
Jackson, 2010: Goldbort 2009). Professionals' manner and communication can significantly affect women's feelings of control during their delivery (Salter 2009) and their ability to make informed decisions (Eliasson, Kainz \& Von Post, 2008). Yet choice, information and involvement in decisions are potentially protective against a traumatic birth experience (Goodall, McVittie \& Magill 2009). Therefore, professionals need to understand that childbirth can be traumatic for women (Elmir et al., 2010); acknowledge the role they may play and recognise the signs of psychological trauma (Beck 2004). There is also evidence that increased empathy in staff can increase their own risk of PTSD symptoms after witnessing traumatic childbirth events (Sheen, Spiby \& Slade, 2014).

In some international contexts, there is a firm policy remit for the assessment of psychological health and identification of perinatal mental health disorder in its broadest sense (eg NICE, 2007; Beyond Blue 2011; Rahman et al., 2013) which assumes that improved detection and assessment leads to improved outcomes. At present this relationship is neither proven nor likely to be linear. Across the spectrum, perinatal mental health detection, treatment and referral remains seriously lacking, is inconsistent and requires attention (Goodman \& Tyler-Viola 2010; NSPCC 2013; Jomeen \& Martin 2014).

Routine questioning in clinical practice to elicit trauma symptoms requires appropriate and available measures (Alderdice et al., 2013). However, these are often not consistently utilised or applied (Rowan, McCourt \& Bick 2010). Several authors propose flexible questioning to facilitate broader consideration of the comorbidities of psychological and complex psychosocial factors (Dennis, Janssen \& Singer, 2004; Robertson, Grace, Wallington \& Stuart 2004), which might be more relevant to the PTSD FC context.

Clinical guidelines refer to PTSD FC pathways for care that appear to be outside the maternity context. The result of this might be that practitioners feel less informed about PTSD FC but also unclear about referral and management options. Lack of training has been identified as a core barrier to addressing issues of perinatal mental illness (Byatt, Moore-Simas, Lundquist Johnson, Ziedonis, 2012). Available and accessible pathways for care and onward referral are also critical for confident practitioner identification and assessment. Evidence highlights that midwives (Jomeen, Glover \& Davies 2009), health visitors (Jomeen, Glover, Jones, Garg \& 
Marshall 2013) and obstetricians (Leddy, Hagga, Gray, Schulkin, 2011) are reluctant to ask women about psychological issues when pathways are not evident.

Deficient care may be a consequence of numerous factors, including psychopathology, time, effective screening measures, referral options or lack of knowledge (Matthey \& Ross-Hamid 2011). Research is needed to evaluate care pathways and training interventions, with reference to sensitive care, effective identification, assessment and management of PTSD FC.

Prevention and Early Intervention

At present, published research on the prevention of PTSD FC is scarce. Most available evidence is on midwife-led postnatal debriefing which suggests women appreciate debriefing but there is inconsistent evidence on whether it reduces symptoms of PTSD FC or depression (Baxter, McCourt \& Jarrett, 2014; Borg Cunen, McNeill \& Murray, 2014; Peeler, Chunt, Stedmon \& Skirton, 2012). A less standardised "postnatal discussion", in which a woman has the opportunity to evaluate the course of labour and delivery, to ask questions and to voice her opinion to a trained professional, is recommended for women who wish to talk about their experiences (NICE, 2007).

A recent RCT of trauma-focused CBT for mothers of preterm infants found a reduction in symptoms of PTSD, depression and anxiety at 1 and 6 months (Shaw, St John, Lilo, Jo, Benitz, Stevenson \& Horwitz, 2014). Ongoing research in this area is examining a number of potential prevention strategies, such as a system of identifying high risk women and training staff to provide empathic care (McKenzieMcHarg, Crockett, Olander \& Ayers, 2014).

Prevention can address a variety of factors, some of which are outlined in previous sections, such as staff training and systemic interventions aimed at whole maternity systems. Prevention strategies targeted at women could include early identification of vulnerable women, additional targeted support from midwifery and psychological services, ensuring compassionate care in labour and interventions early in the postnatal period such as postnatal discussion which could encourage women to process any traumatic experience and have the possibility of reducing later symptoms. Any such interventions should also be aimed at changing factors that 
play a role in women's appraisals, including the need for maternity staff to create realistic expectations of delivery.

One example of an intervention which aims to address the need for realistic expectations is that of a 'birth flow chart' rather than a 'birth plan', with different pathways for 'what if labour starts with induction / preterm / ends with caesarean section' etc. (Thomson \& Downe, 2010). It is important that approaches to birth consider a range of possible processes and outcomes, rather than focusing on a single expected outcome which can result in women going into labour with an idealistic picture of natural childbirth (Frost, Pope, Liebling \& Murphy, 2006).

The group acknowledged the need to map current perinatal provision, in order to understand the messages women are receiving antenatally, but also during and after delivery. A number of researchers have explored the role of support antenatally and in labour (lles, Spiby \& Slade, 2013) and this work is continuing.

Despite increasing knowledge of PTSD FC, very few professional support services are available to help women postnatally or prior to a subsequent birth (Thomson \& Downe 2008). Limited fear of childbirth interventions exist within maternity services, emerging from the premise that fear in childbirth is both a consequence of (Elmir et al., 2010) and a risk factor for trauma symptoms (Otley, 2012; Fisher, Hauck \& Fenwick 2006). Despite a somewhat inconsistent evidence base (Otley, 2012) these offer one pathway of care for PTSD FC.

For future clinical and research purposes, strategies for early intervention may be adapted from studies in other trauma populations. The optimal timing of treatment and intervention for PTSD FC remains a topic of debate. Intervening in the very early postnatal period may have the potential to pathologise and disrupt normal cognitive mechanisms of adjustment. It potentially disregards the fact that most women do not develop long term trauma responses following a difficult delivery. However, as $9-14 \%$ of women report labour as traumatic (Boorman et al., 2014; Stramrood et al., 2011) a further approach could involve staff offering these women appropriate referral.

$\underline{\text { Impact on Families and Infants }}$

Traumatic birth may have negative implications for maternal and infant health, reproductive choices and relationships with infants and partners. Recent meta- 
syntheses highlight the emotional impact on women, with reports of anger, selfblame, suicidal ideation, loss of positive affect, isolation and dissociation from others (Elmir et al., 2010; Fenech \& Thomson, 2014). Future reproductive choices may be affected, with women delaying or avoiding future pregnancies due to fear. In extreme cases this can lead to women contemplating sterilisation (Fenech \& Thomson, 2014).

Women's relationships may also be affected. Qualitative research suggests women can struggle to form a positive relationship with their infant (Elmir et al., 2010; Fenech \& Thomson, 2014), although the role of comorbid depression is unclear (Davies, Slade, Wright \& Stewart, 2008; Parfitt \& Ayers, 2009). PTSD FC can negatively impact on relationships with partners; avoidance of sex and intimacy are common due to fear of conception and triggering PTSD symptoms (Elmir et al., 2010; Fenech \& Thomson, 2014). Studies of male partners show high levels of co-morbidity within couples and men's PTSD responses may affect the mental health of their partner (Iles, Slade \& Spiby, 2011). Men also report PTSD responses (Stramrood et al., 2013; White, 2007), but evidence of the scope of these is mixed (Bradley and Slade 2008. Similarly impact is not clearcut. For example, Parfitt and colleagues found that although PTSD was associated with a worse self-reported parent-baby bond (Parfitt \& Ayers, 2009) it was not associated with an observational measure of parent-infant interaction (Parfitt, Pike \& Ayers, 2013a).

The long-term impact on infants is not well evidenced. Qualitative research suggests women might have difficulties bonding and/or avoid breastfeeding (Beck \& Watson, 2008), which can have long-term health implications for infants (Horta, Bahl, Martines \& Victora, 2007; Ip et al., 2007). Longitudinal studies of the impact of PTSD on infants suggest symptoms may be associated with parenting stress at two years, but do not affect mothers' perceptions of their infant (McDonald, Slade, Spiby \& Iles, 2011). A study of infant development found PTSD FC was associated with poor cognitive development at 17 months of age (Parfitt, Pike \& Ayers, 2013b).

Conclusions about the impact of PTSD on the mother-baby relationship, couple's relationship and child development remain tentative because of the limited evidence available. Whilst there is substantial qualitative research showing a traumatic birth can have a wide-ranging impact on women and their families, more quantitative research is needed to confirm and extend these findings. In particular, prospective studies with larger, representative samples are needed to establish the extent and nature of the impact of PTSD on the couple's relationship and infant development. Studies are needed that examine gaps between index and subsequent children; the 
impact of trauma on infant's developmental outcomes within term, pre-term and vulnerable population groups (e.g. bereaved or abused mothers); the course and impact of male partners' PTSD responses; the combined effect of co-morbidity (particularly depression) on familial relationships; other birth partners (i.e grandparents, sisters); as well as the intergenerational implications of trauma.

\section{Special Populations}

High-risk populations are increasingly focused on, including women with preeclampsia, preterm or stillbirth. Here we consider stillbirth and preterm birth.

\section{Stillbirth}

The global prevalence rate of stillbirths (in the UK, a baby born after 24 weeks with no signs of life) is 2.64 million (Cousens et al., 2011). Most research has focused on the psychological impact of stillbirth on parents and the wider family system, highlighting grief, loss of self-esteem, and feelings of worthlessness, isolation, shame and guilt (Cacciatore, 2010). Depression, anxiety, PTSD and traumatic grief have also been reported (Campbell-Jackson \& Horsch, 2014).

As understanding about care after stillbirth has developed, there is a need to disentangle traumatic grief and post traumatic stress at a conceptual level. The International Society for Traumatic Stress Studies describes traumatic grief as the sudden and unexpected death of a significant other - usually a close family member. While many of the symptoms of traumatic grief overlap with PTSD, the core symptoms of traumatic grief are an unquenchable yearning or longing for the dead person that preoccupies much of a person's waking life. It is not typical to experience reliving or avoidance phenomena in the way that those experiencing PTSD do. There is very little research which aims to disentangle the two, and only a small number of studies examine both PTSD and traumatic grief within the same cohort (Campbell-Jackson \& Horsch, 2014; Horsch, McKenzie-McHarg \& Jacob, in press)

Guidelines surrounding maternal contact with the stillborn infant have been contradictory (NICE, 2007) and evidence as to whether seeing and holding the stillborn baby is associated with maternal anxiety and depressive symptoms has been inconclusive. A recent study on the maternal experience of this contact found 
that the majority felt satisfied with their decision to see or hold their stillborn (Ryninks, Collins, McKenzie-McHarg \& Horsch, 2014) and another emphasised the importance of sharing memories of the stillborn baby to aid psychological adjustment (Crawley, Lomax \& Ayers, 2013). Efforts have increased to better understand the risk factors and predictors of traumatic grief after stillbirth (Crispus-Jones, McKenzie-McHarg \& Horsch, under review), but more are needed. Recent studies have focused on the impact of stillbirth on antenatal attachment during the subsequent pregnancy and on parenting a subsequent child (Campbell-Jackson, Bezance \& Horsch, under review; Lee \& Horsch, under review).

Most research to date has grouped together all forms of perinatal loss and the psychological impact of early versus late loss requires further clarification. More longitudinal studies and those using validated measures and incorporating diverse samples are needed. More research examining the impact of changes in guidelines and care offered to bereaved parents linked with psychological theory should be encouraged.

\section{Preterm Birth}

Preterm birth (prior to 37 weeks gestation) is the most important determinant of adverse outcome in terms of survival, quality of life, psychosocial and emotional impact on the family and costs for health services. In Europe the preterm birth rate for live births ranges from approximately $5 \%$ to $11 \%$ (Zeitlin et al., 2013). PTSD and depression in pregnancy are also associated with an increased risk of preterm birth (Yonkers, Smith, Forray, Epperson, Costello, Lin \& Belanger, 2014).

Preterm birth and hospitalisation of the baby can be a distressing time for parents. Research on psychological adjustment following preterm birth has focused on depression and anxiety. Fewer studies have explored maternal trauma reactions. Studies report high and persistent rates of PTSD (Elkit, Hartvig, \& Christiansen, 2007; Forcada-Guex, Borghini, Pierrehumbert, Anserment, \& Muller-Nix, 2011; Jotzo \& Poets, 2005; Misund, Nerdrum, Bratten, Pipp, \& Diseth, 2013). Associations between PTSD symptoms, a poor mother-infant relationship, and adverse infant outcomes have also been reported (Feeley et al., 2011; Forcada-Guex et al., 2011; Pierrehumbert, Nicole, Muller-Nix, Forcada-Guex \& Anserment, 2003). 
More studies are needed to identify risk factors for traumatic stress responses following preterm birth. Current research suggests a higher level of prematurity, low social support, dysfunctional coping, preeclampsia, bleeding in pregnancy, and intraventricular hemorrhage in babies associated with higher levels of PTSD symptoms (Misund et al., 2013; Shaw, Bernard, Storfer-Isser, Rhine, \& Horwitz, 2013; Suttora, Spinelli, \& Monzani, 2014). There is a higher incidence of preterm birth in certain ethnic groups and in women from very deprived areas (Aveyard, Cheng, Manaseki, \& Gardosi, 2002; Smith, Draper, Manktelow, Dorling \& Field, 2007). However, most research exploring PTSD has been conducted with White, married, highly educated mothers and research is needed with more diverse groups. Finally, guidelines for screening for trauma symptoms in mothers of preterm infants are absent. As there are currently no clear maternal or infant predictors, one option is to screen all mothers of preterm infants (Shaw et al., 2014).

\section{Post-Traumatic Growth}

Research on psychological adjustment following childbirth has predominantly focused on negative outcomes, and positive outcomes have been relatively ignored. A positive outcome that may be particularly relevant to birth is personal growth. Growth is defined as positive change resulting from struggle with challenging events (Tedeschi \& Calhoun, 1996) and has been variously conceptualised as 'benefitfinding', 'thriving' and 'posttraumatic growth' (PTG).

Evidence that positive outcomes and growth occur after birth is increasing. A population survey of 5333 women found that approximately one third reported a positive outcome after birth (Henderson \& Redshaw, 2013). Qualitative research on women's experiences following traumatic births supports this with positive outcomes such as a sense of strength or purpose being reported (Beck \& Watson, 2010; Thomson \& Downe, 2010; Thomson \& Downe, 2013; Elmir et al., 2010).

Very few studies have examined growth directly using validated instruments such as the posttraumatic growth inventory (PTGI). The PTGI measures five areas: New Possibilities, Relating to Others, Personal Strength, Spiritual Change, and Appreciation of Life. Studies confirm that approximately $50 \%$ of women report at least moderate levels of growth, and scores are broadly comparable to other samples e.g. after accidents (Sawyer \& Ayers, 2009). Women report most growth in the Appreciation of Life and Personal Strength domains, and the least in the Spiritual Change domain (Sawyer \& Ayers, 2009; Sawyer, Ayers, Young, Bradley, \& Smith, 
2012; Taubman-Ben-Ari, Findler, \& Sharon, 2011). More growth is reported by women with more difficult circumstances e.g. mothers of preterm babies (Spielman \& Taubman-Ben-Ari, 2009), women who have PTSD in pregnancy or caesarean section births (Sawyer et al., 2012).

However, research on growth following childbirth is limited and important gaps remain around conceptualisation and measurement, predictors, and how growth can be incorporated into clinical interventions. Conceptually, the relationship between growth and resilience is unclear (Westphal \& Bonanno, 2007). The applicability and validity of measures of growth with postnatal women needs to be explored further (Taubman-Ben-Ari et al., 2011). More qualitative research is needed to provide insights into the nature of positive changes following childbirth.

Finally, although the literature is equivocal regarding the relationship between growth and distress, a number of notable longitudinal studies in non-obstetric populations have found that growth following a stressful event is predictive of better emotional adjustment in the long term (e.g. Danoff-Burg \& Revenson, 2005; Frazier, Conlon \& Glaser, 2001), and there are promising studies integrating growth into clinical interventions (Roepke, 2014). However, before growth can be recommended as a viable therapeutic option for women with PTSD FC more prospective and longitudinal studies are needed to understand the relationship between growth and distress.

\section{Summary}

This paper provides an update of Ayers et al. (2008) and reports on the four primary areas identified then. In addition, five further areas of research are discussed which we consider important in PTSD FC research. This paper highlights areas in which our understanding of PTSD has increased, as well as those where more research is needed. These include a wide range of issues, such as the development of robust measures for the identification of risk factors and PTSD FC, as well as consideration of sub-threshold symptomatology. The evaluation of theoretically informed insights into PTSD FC are needed, as well as exploration into the potential for positive outcomes. Longitudinal studies are required to assess prevalence, intensity and severity of PTSD as well as impact on mothers, infants, fathers and others within diverse population groups. Further areas that require consideration concern the integration of PTSD FC within maternity care pathways together with suitable training for maternity professionals, alternative approaches to prepare mothers for childbirth 
and further testing to identify the timing of and suitable and effective intervention approaches.

1

2

3

4

5

6

7

8

9

10

11

12

13

14

15

16

17

18

19

20

21

22

23

24

25

26

27

28

29

30

31

32

33

34

35

36

37

38

39

40

41

42

43

44

45

46

47

48

49

50

51

52

53

54

55

56

57

58

59

60

URL: http://mc.manuscriptcentral.com/cjri E-mail: support@scholarone.com 


\section{References}

Alderdice, F., Ayers, S., Darwin, Z., Green, J., Jomeen, J., Kenyon, S., Martin, C.R., Morrell, C.J., Newham, J.J., Redshaw, M., Savage-McGlynn, E., \& Walsh, J. (2013). Measuring psychological health in the perinatal period: workshop consensus statement. Journal of Reproductive and Infant Psychology, 31(5), 431-438.

DOI: 10.1080/02646838.2013.835039

American Psychiatric Association, (2013). Diagnostic and Statistical Manual of Mental Disorders, Fifth Edition. Arlington: APA.

Aveyard, P., Cheng, K. K., Manaseki, S., \& Gardosi, J. (2002). The risk of preterm delivery in women from different ethnic groups. British Journal of Obstetrics and Gynaecology, 109, 894-899. DOI: 10.1111/j.1471-0528.2002.01197.x

Ayers, S. (2004). Delivery as a Traumatic Event: Prevalence, Risk Factors and Treatment for Postnatal Posttraumatic Stress Disorder. Clinical Obstetrics and Gynecology, 47(3), 552-567. DOI: 10.1097/01.grf.0000129919.00756.9c

Ayers, S., Harris, R., Sawyer, A., Parfitt, Y., \& Ford, E. (2009). Posttraumatic stress disorder after childbirth: Analysis of symptom presentation and sampling. Journal of Affective Disorders 119: 200-204. doi:10.1016/j.jad.2009.02.029

Ayers, S. \& Ford E. Posttraumatic stress during pregnancy and the postpartum period. , in Oxford Handbook of Perinatal Psychology, A. Wenzel and S. Stuart, Editors. in press, Oxford University Press: New York.

Ayers, S., Joseph S., McKenzie-McHarg K., Slade, P., \& Wijma K. (2008). Posttraumatic stress disorder following childbirth: current issues and recommendations for future research. Journal of Psychosomatic Obstetrics \& Gynecology, 29(4), 240250. DOI:10.1080/01674820802034631

Ayers, S., McKenzie-McHarg, K., Eagle, A. (2007). Cognitive behaviour therapy for postnatal post-traumatic stress disorder: case studies. Journal of Psychosomatic Obstetrics \& Gynaecology; 28, 177-184. DOI:10.1080/01674820601142957 
Baxter, J.D., McCourt, C., \& Jarrett, P.M. (2014). What is current practice in offering debriefing services to post partum women and what are the perceptions of women in accessing these services: a critical review of the literature.

Midwifery. 30(2),194-219. DOI: 10.1016/j.midw.2013.12.013. Epub 2013 Dec 27.

Beck T.C. (2004). Birth trauma: in the eye of the beholder. Nursing Research. 53(1), 28-35. DOI: 10.1097/00006199-200401000-00005

Beck, C. T., \& Watson, S. (2008). Impact of birth trauma on breastfeeding. A tale of two pathways. Nursing Research, 57, 228-236.

DOI: 10.1097/01.NNR.0000313494.87282.90

Beck, C. T., \& Watson, S. (2010). Subsequent childbirth after a previous traumatic birth. Nursing Research, 59, 241-249. DOI: 10.1097/NNR.0b013e3181e501fd

Beyond Blue (2011). Clinical practice guidelines for depression and related disorders - anxiety, bipolar disorder and puerperal psychoses - in the perinatal period. A guideline for primary care professionals. Melbourne, beyondblue: the national depression initiative

Boorman, R.J., Devilly, G.J., Gamble, J., Creedy, D.K., \& Fenwick, J. (2014).

Childbirth and criteria for traumatic events. Midwifery; 30:255-261.

doi:10.1016/j.midw.2013.03.001

Borg Cunen, N., McNeill, J., \& Murray, K. (2014). A systematic review of midwifeled interventions to address post partum post-traumatic stress. Midwifery. 30(2),17084. DOI: 10.1016/j.midw.2013.09.003. Epub 2013 Sep 21.

Bradley, R., Slade, P. \& Leviston, A. (2008). Low rates of PTSD in men attending childbirth: preliminary study. British Journal of Clinical Psychology, 47, 295-302.

DOI: $10.1348 / 014466508 \times 279495$

Brewin, C.R. (2001). A cognitive neuroscience account of posttraumatic stress disorder and its treatment. Behaviour Research and Therapy, 39, 373-393.

DOI: 10.1016/S0005-7967(00)00087-5 
Byatt, N., Moore Simas, T.A., Lundquist, R.S., Johnson, J.V., \& Ziedonis, D.M., (2012) Strategies for improving perinatal depression treatment in North American outpatient obstetric settings. Journal of Psychosomatic Obstetrics \& Gynecology. 33 (4), 143-161. DOI:10.3109/0167482X.2012.728649

Cacciatore, J. (2010). The unique experiences of women and their families after the death of a baby. Social Work and Health Care, 49, 134-48.

DOI: $10.1080 / 00981380903158078$

Campbell-Jackson, L. \& Horsch, A. (2014). The psychological impact of stillbirth: A systematic review. Illness, Crisis and Loss, 22, 237-256.

Campbell-Jackson, L., Bezance, J., \& Horsch, A. "A renewed sense of purpose": Mothers' and fathers' experience of having a child following a recent stillbirth. Under review.

Charuvastra, A., \& Cloitre, M. (2008). Social Bonds and Posttraumatic Stress Disorder. Annual Review of Psychology. 59: 301-328.

DOI: 10.1146/annurev.psych.58.110405.085650

Cousens, S., Blencowe, H., Stanton, C., Chou, D., Ahmed, S., Steinhardt, L., ... \& Lawn, J.E. (2011). National, regional, and worldwide estimates of stillbirth rates in 2009 with trends since 1995: a systematic analysis. Lancet, 377, 1319-1330.

DOI: 10.1016/S0140-6736(10)62310-0

Crawley, R., Lomax, S., \& Ayers, S. (2013). Recovering from stillbirth: the effects of making and sharing memories on maternal mental health. Journal of Reproductive and Infant Psychology, 31, 195-207. DOI:10.1080/02646838.2013.795216.

Crispus-Jones, H., McKenzie-McHarg, K., \& Horsch, A. Psychological and obstetric predictors of complicated grief following stillbirth. Journal of Reproductive and Infant Psychology. Under review.

Danoff-Burg, S., \& Revenson, T. A. (2005). Benefit-finding among patients with rheumatoid arthritis: Positive effects on interpersonal relationships. Journal of Behavioral Medicine, 28, 91-103. DOI: 10.1007/s10865-005-2720-3 
Davies, J., Slade, P., Wright, I., \& Stewart, P. (2008). Posttraumatic stress symptoms following childbirth and mothers' perceptions of their infant. Infant Mental Health Journal, 29, 537-554. DOI: 10.1002/imhj.20197

Dennis, C-L., Janssen, P., \& Singer, J. (2004). Identifying women at-risk for postpartum depression in the immediate postpartum period. Acta Psychiatrica Scandinavica, 110, 338-346. DOI: 10.1111/j.1600-0447.2004.00337.x

Ehlers, A. \& Clark, D.M. (2000). A cognitive model of posttraumatic stress disorder. Behaviour Research and Therapy. 38(4): 319-345.

DOI: 10.1016/S0005-7967(99)00123-0

Eliasson, M., Kainz, G. \& Von Post, I. (2008). Uncaring midwives. Nursing Ethics. 15(4), 501-511. DOI: 10.1177/0969733008090521

Elklit, A., Hartvig, T., \& Christiansen, M. (2007). Psychological sequelae in parents of extreme low and very low birth weight infants. Journal of Clinical Psychology in Medical Settings, 14, 238-47. DOI: 10.1007/s10880-007-9077-4

Elmir, R., Schmied, V., Wilkes, L., \& Jackson, D. (2010). Women's perceptions and experiences of a traumatic birth: A meta-ethnography. Journal of Advanced Nursing, 66, 2142-2153. DOI: 10.1111/j.1365-2648.2010.05391.x

Feeley, N., Zelkowitz, P., Cormier, C., Charbonneau, L., Lacroix, A., \& Papageorgiou, A. (2011). Posttraumatic stress among mothers of very low birthweight infants at 6 months after discharge from the neonatal intensive care unit. Applied Nursing Research, 24, 114-117. DOI: http://dx.doi.org/10.1016/j.apnr.2009.04.004

Fenech, G., \& Thomson, G. (2014). 'Tormented by Ghosts of their Past': A metasynthesis to explore the psychosocial implications of a traumatic birth on maternal wellbeing. Midwifery, 30,185-193. DOI:10.1016/j.midw.2013.12.004

Fisher, C., Hauck, Y., \& Fenwick, J. (2006). How social context impacts on women's fears of childbirth: a Western Australian example. Social Science and Medicine, 63(1), 64-75. DOI: 10.1016/j.socscimed.2005.11.065 
Forcada-Guex, M., Borghini, A., Pierrehumbert, B., Ansermet, F., \& Muller-Nix, C. (2011). Prematurity, maternal posttraumatic stress and consequences on the mother-infant relationship. Early Human Development, 87, 21-6.

DOI: http://dx.doi.org/10.1016/j.earlhumdev.2010.09.006

Ford, E., Ayers, S., \& Bradley, R. (2010). Exploration of a cognitive model to predict post-traumatic stress symptoms following childbirth. Journal of Anxiety Disorders, 24(3): 353-359. DOI: 10.1016/j.janxdis.2010.01.008

Frazier, P., Conlon, A., \& Glaser, T. (2001). Positive and negative life changes following sexual assault. Journal of Consulting and Clinical Psychology, 69, 10481055. DOI: $10.1037 / 0022-006 X .69 .6 .1048$

Frost, J., Pope, C., Liebling, R., \& Murphy, D.J. (2006). Utopian Theory and the Discourse of Natural Birth. Social Theory \& Health; 4(4); 299-318.

DOI: http://dx.doi.org/10.1057/palgrave.sth.8700076

Gamble, J., \& Creedy, D. (2004). Content and processes of postpartum counseling after a distressing birth experience: a review. Birth;31:213-218. DOI: 10.1111/j.07307659.2004.00307.x

Gamble, J., Creedy, D., Moyle, W., Webster, J., McAllister, M., \& Dickson, P. (2005). Effectiveness of a counseling intervention after a traumatic childbirth: a randomized controlled trial. Birth; 32:11-19. DOI: 10.1111/j.0730-7659.2005.00340.x

Gamble, J.A., Creedy, D.K., Webster, J., \& Moyle, W. (2002). A review of the literature on debriefing or non-directive counselling to prevent postpartum emotional distress. Midwifery;18:72-79. DOI: 10.1054/midw.2001.0287

Goldbort J.G. (2009). Women's lived experience of their unexpected birthing process. The American Journal of Maternal / Child Nursing. 34(1), 57-62.

DOI: 10.1097/01.NMC.0000343867.95108.b3

Goodall E.K., McVittie C., \& Magill M. (2009). Birth choice following primary caesarean section: mothers' perceptions of the influence of health professionals on decision making. Journal of Reproductive and Infant Psychology. 27(1), 4-14. 
DOI: $10.1080 / 02646830801918430$

Goodman, J.H., \& Tyer-Viola, L. (2010). Detection, Treatment, and Referral of Perinatal Depression and Anxiety by Obstetrical Providers. Journal of Women's Health. 19(3), 477-490. DOI:10.1089/jwh.2008.1352.

Grekin, R., \& O'Hara, M.W. (2014). Prevalence and risk factors of postpartum posttraumatic stress disorder: a meta-analysis. Clinical Psychology Review, 34(5), 389-401. DOI: 10.1016/j.cpr.2014.05.003

Henderson, J., \& Redshaw, M. (2013). Who is well after childbirth? Factors related to positive outcome. Birth, 40, 1-9. DOI: 10.1111/birt.12022

Horowitz, M.J., Psychological response to serious life events. In Human Stress and Cognition: An Information Processing Approach., V. Hamilton and D.M. Warburton, Editors. 1979, Wiley: New York.

Horsch, A., Jacobs, I., \& McKenzie-McHarg, K. (under review). Cognitive predictors and risk factors of PTSD and its relationship with perinatal grief following stillbirth: $A$ longitudinal study. Journal of Traumatic Stress

Horta, B. L., Bahl, R., Martinés, J. C. \& Victora, C. G. (2007). Evidence on the longterm effects of breastfeeding: Systematic reviews and meta-analysis. World Health Organization: Geneva.

lles, J., Slade, P., \& Spiby, H. (2011). Posttraumatic stress symptoms and postpartum depression in couples after childbirth: The role of partner support and attachment. Journal of Anxiety Disorders, 25(4), 520-530.

DOI: 10.1016/j.janxdis.2010.12.006

Iles, J., Slade, P., \& Spiby, H. (in press). Modification and preliminary use of the fiveminute speech sample in the postpartum: associations with postnatal depression and posttraumatic stress. Archives of Women's Mental Health.

DOI: $10.1007 / s 00737-014-0414-y$ 
Ip, S., Chung, M., Raman, G., Chew, P., Magula, N. ... \& Lau, J. (2007).

Breastfeeding and maternal and infant health outcomes in developed countries.

Evidence Report - Technology Assessment. 153, 1-186.

Janoff-Bulman, R. (1992). Shattered assumptions : towards a new psychology of trauma. New York: Free Press.

Jomeen, J., Glover, L., \& Davies, S. (2009). Midwives' illness perceptions of antenatal depression. British Journal of Midwifery. 17(5), 296-303.

DOI: http://dx.doi.org/10.12968/bjom.2009.17.5.42221

Jomeen, J., Glover, L., Jones, C., Garg, D. \& Marshall, C. (2013). Assessing women's perinatal psychological health: exploring the experiences of health visitors. Journal of Reproductive and Infant Psychology. 31 (5), 479-489.

DOI: $10.1080 / 02646838.2013 .835038$

Jomeen, J., \& Martin C.R. (2014). Developing specialist perinatal mental health services. Practising Midwife. 17(3), 18-21.

Joseph, S., \& Linley, P. A. (2008). Reflections on theory and practice in trauma, recovery, and growth: A paradigm shift for the field of traumatic stress. In S. Joseph \& P. A. Linley (Eds.), Trauma, recovery and growth: Positive psychological perspectives on posttraumatic stress (pp. 339-356). Hoboken, NJ: John Wiley \& Sons.

Jotzo, M., \& Poets, C. F. (2005). Helping parents cope with the trauma of premature birth: an evaluation of a trauma-preventive psychological intervention. Pediatrics, 115, 915-19. DOI: 10.1542/peds.2004-0370

Kenworthy Teather, E. (2005) Embodied geographies. Routledge.

Lazarus, R. \&. Folkman, S. (1984). Stress, appraisal and coping. New York: Springer Publishing.

Leddy, M., Hagga, D., Gray, J, \& Schulkin, J. (2011). Postpartum mental health screening and diagnosis by obstetrican-gynecologists. Journal of Psychosomatic Obstetrics and Gynaecology. 32(1), 27-34. DOI:10.3109/0167482X.2010.547639 
Lee, L., \& Horsch, A. The impact of miscarriage and stillbirth on the parent-foetal bond. An integrative review. Under review.

Matthey, S. \& Ross-Hamid, C. (2011). The validity of DSM symptoms for depression and anxiety disorders during pregnancy. Journal of Affective Disorders. 133(3), 546552. DOI: 10.1016/j.jad.2011.05.004

McDonald, S., Slade, P., Spiby, H., \& Iles, J. (2011). Post-traumatic stress symptoms, parenting stress and mother-child relationships following childbirth and at 2 years postpartum. Journal of Psychosomatic Obstetrics \& Gynaecology, 32(3), 141-146. DOI:10.3109/0167482X.2011.596962

McKenzie-McHarg, K., Crockett, M., Olander, E., \& Ayers, S. (2014). Think Pink!: a pink sticker alert system for women with psychological distress or vulnerability during pregnancy. British Journal of Midwifery. In press.

Misund, A. R., Nerdrum, P., Braten, S., Pripp, A. H., \& Diseth, T. H. (2013). Longterm risk of mental health problems in women experiencing preterm birth: $A$ longitudinal study of 29 mothers. Annals of General Psychiatry, 12, 33-41. Found at http://www.annals-general-psychiatry.com/content/12/1/33

National Institute for Health and Clinical Excellence (2005). Post-traumatic stress disorder (PTSD): The management of PTSD in adults and children in primary and secondary care. London: Department of Health

National Institute for Health and Clinical Excellence, (2007). Antenatal and Postnatal Mental Health; Clinical Management and Service Guidance. London: Department of Health.

NSPCC (2013). Prevention in Mind. Available from:

http://www.nspcc.org.uk/Inform/resourcesforprofessionals/underones/spotlightmental-health-landing_wda96578.html

Oldea, E., van der Harta, O.,Klebera, R., \& van Sona, M. (2006). Posttraumatic stress following childbirth: A review. Clinical Psychology Review, 26(1), 1-16. 
Otley, $\mathrm{H}$ (2012). Fear of childbirth: understanding the causes, impact and treatment. British Journal of Midwifery. 19(4). Available from http://www.babybirth.com/articles/54-antenatal/321-fear-of-childbirth-understanding-the-causesimpact-and-treatment.html. DOI: 10.12968/bjom.2011.19.4.215

Parfitt, Y., \& Ayers, S. (2009). The effect of post-natal symptoms of post-traumatic stress and depression on the couple's relationship and parent-baby bond. Journal of Reproductive and Infant Psychology, 27(2), 127-142.

DOI: $10.1080 / 02646830802350831$

Parfitt, Y., Pike, A., \& Ayers, S. (2013a). The impact of parents' mental health on parent-baby interaction: A prospective study. Infant Behavior and Development, 36, 599 - 608. DOI: 10.1016/j.infbeh.2013.06.003

Parfitt, Y., Pike, A. \& Ayers, S. (2013b). Infant developmental outcomes: a family systems perspective. Infant and Child Development. DOI: 10.1002/icd.1830.

Parratt, J.A. (2008). Territories of the self and spiritual practices during childbirth. Birth Territory and Midwifery Guardianship: Theory for practice, education and research Edinburgh: Butterworth Heinemann Elsevier, pp 39-54.

Peeler, S., Chung, M.C., Stedmon, J., \& Skirton, H. (2013). A review assessing the current treatment strategies for postnatal psychological morbidity with a focus on post-traumatic stress disorder. Midwifery. 29(4), 377-88.

DOI: 10.1016/j.midw.2012.03.004. Epub 2012 Nov 21.

Pierrehumbert, B., Nicole, A., Muller-Nix, C., Forcada-Guex, M., \& Ansermet, F. (2003). Parental post-traumatic reactions after premature birth: Implications for sleeping and eating problems in the infant. Archives of Disease in Childhood-Fetal and Neonatal Edition, 88, F400-F404. DOI:10.1136/fn.88.5.F400

Rahman A., Surkan, P.J., Cayetano, C.E., Rwagatare, P., \& Dickson, K.E. (2013). Grand Challenges: Integrating Maternal Mental Health into Maternal and Child Health Programmes. PLoS Med 10(5): e1001442. DOI:10.1371/journal.pmed.1001442 
Robertson, E., Grace, S., Wallington, T., \& Stewart, D.E. (2004) Antenatal risk factors for postpartum depression: A synthesis of recent literature. General Hospital Psychiatry, 26, 289-295. DOI:10.1016/j.genhosppsych.2004.02.006

Roepke, A. M. (2014). Psychosocial interventions and posttraumatic growth: A metaanalysis. Journal of Consulting and Clinical Psychology. Advance online publication. http://dx.doi.org/10.1037/a0036872

Rowan, C., McCourt, C. \& Bick, D. (2010). Provision of perinatal mental health services in two strategic health authorities: views and perspectives of the multiprofessional team. Evidence Based Midwifery, 8(3), 98-106.

Ryninks, K., Collins, C., McKenzie-McHarg, K., \& Horsch, A. (2014). Mothers' experience of their contact with their stillborn infant. BMC Pregnancy and Childbirth, 14: 203. DOI: 10.1186/1471-2393-14-203.

Sandstrom, M., Wiberg, B., Wikman, M., Willman, A.K., \& Hogberg, U. (2008). A pilot study of eye movement desensitisation and reprocessing treatment (EMDR) for posttraumatic stress after childbirth. Midwifery, 24, 62-73.

Salter, K. (2009). Beating the trauma of a bad birth experience. Mental Health Today, September, 14-15.

Sawyer, A., \& Ayers, S. (2009). Post-traumatic growth in women after childbirth. Psychology \& Health, 24, 457-471. DOI: 10.1080/08870440701864520

Sawyer, A., Ayers, S., Young, D., Bradley, R., \& Smith, H. (2012). Posttraumatic growth after childbirth: A prospective study. Psychology and Health, 27, 362-377. DOI: $10.1080 / 08870446.2011 .578745$

Shaw, R. J., Lilo, E, A., Storfer-Isser, A., Ball, M. B., Proud, M. S. ... \& Horwitz, S. (2014). Screening for symptoms of postpartum traumatic stress in a sample of mothers with preterm infants. Issues in Mental Health Nursing, 35, 198-207.

DOI: 10.3109/01612840.2013.85332 
Shaw, R. J., Bernard, R. S., Storfer-Isser, A., Rhine, W., \& Horwitz, S. M. (2013).

Parental coping in the neonatal intensive care unit. Journal of Clinical Psychology in Medical Settings, 20,135-142. DOI: 10.1007/s10880-012-9328-x

Shaw, R. J., Lilo, E.A., Storfer-Isser, A., Ball, M. B., Proud, M. S. ... \& Horwitz S.M. (2014). Screening for symptoms of postpartum traumatic stress in a sample of mothers with preterm infants. Issues in Mental Health Nursing, 35, 198-206.

DOI:10.3109/01612840.2013.853332

Shaw, R.J., St John, N., Lilo, E., Jo, B., Benitz, W. ... \& Horwitz, S.M. (2014). Prevention of traumatic stress in mothers of preterms: 6-month outcomes.

Pediatrics. pii: peds.2014-0529. [Epub ahead of print]

Sheen, K., Spiby, H., \& Slade, P. (2014). An integrative review of the impact of indirect trauma exposure in health professionals and potential issues of salience for midwives Journal of Advanced Nursing. 709(4), 729-743. DOI: 10.1111/jan.12274

Slade, P. (2006). Towards a conceptual framework for understanding post-traumatic stress symptoms following childbirth and implications for further research. Journal of Psychosomatic Obstetrics and Gynecology, 27(2): 99-105.

DOI:10.1080/01674820600714582

Smith, L. K., Draper, E. S., Manktelow, B. N., Dorling, J. S., \& Field, D. J. (2007). Socioeconomic inequalities in very preterm birth rates. Archives of Disease in Childhood: Fetal and Neonatal Edition, 92, F11-F14. DOI:10.1136/adc.2005.090308

Soderquist, J. (2006). The longitudinal course of post-traumatic stress after childbirth. Journal of Psychosomatic Obstetrics \& Gynaecology;27(2),113-9

Spielman, V., \& Taubman-Ben-Ari, O. (2009). Parental self-efficacy and stressrelated growth in the transition to parenthood: A comparison between parents of preand full-term babies. Health and Social Work, 34, 201-212.

DOI: $10.1093 / \mathrm{hsw} / 34.3 .201$

Stramrood, C.A., Doornbos, B., Wessel, I., van Geenen, M., Aarnoudse, J.G. ... \& van Pampus, M.G. (2013). Fathers with PTSD and depression in pregnancies 
complicated by preterm preeclampsia or PPROM. Archives of Gynecology and Obstetrics,_287(4), 653-61. DOI: 10.1007/s00404-012-2611-0

Stramrood, C.A., Paarlberg, K.M., Huis In 't Veld E.M., Berger, L.W., Vingerhoets, A.J. ...\& van Pampus, M.G. (2011). Posttraumatic stress following childbirth in homelike- and hospital settings. Journal of Psychosomatic Obstetrics and Gynaecology; 32, 88-97. DOI:10.3109/0167482X.2011.569801

Stramrood, C.A., van der Velde, J., Doornbos, B., Paarlberg, K.M., Weijmar Schultz, W.C., \& van Pampus, M.G. (2012). The patient observer: eye-movement desensitization and reprocessing for the treatment of posttraumatic stress following childbirth. Birth; 39, 70-76.

Stramrood, C.A.I., Wessel, I., Doornbos, B., Aarnoudse, J.G., van den Berg P.P. ... \& van Pampus, M.G. (2011). Posttraumatic stress disorder following preeclampsia and PPROM: a prospective study with 15 months follow-up. Reproductive Sciences, 18(7): 645-653. DOI: 10.1177/1933719110395402

Suttora, C., Spinelli, M., \& Monzani, D. (2014). From prematurity to parenting stress: The mediating role of perinatal post-traumatic stress disorder. European Journal of Developmental Psychology, 11, 478-493. DOI: 10.1080/17405629.2013.859574

Taubman-Ben-Ari, O., Findler, L., \& Sharon, N. (2011). Personal growth in mothers: examination of the suitability of the posttraumatic growth inventory as a measurement tool. Women and Health, 51(6), 622.

DOI:10.1080/03630242.2011.614324

Tedeschi, R. G., \& Calhoun, L. G. (1996). The Posttraumatic Growth Inventory: Measuring the positive legacy of trauma. Journal of Traumatic Stress, 9, 455-472. DOI: $10.1007 / \mathrm{BF} 02103658$

Thomson,G., \& Downe, S. (2008) Widening the trauma discourse: the link between childbirth and experiences of abuse. Journal of Psychosomatic Obstetrics and Gynecology. 29(4), 268-273. DOI:10.1080/01674820802545453 
Thomson, G., \& Downe, S. (2010). Changing the future to change the past: women's experiences of a positive birth following a traumatic birth experience. Journal of Reproductive and Infant Psychology, 28, 102-112.

DOI: $10.1080 / 02646830903295000$

Thomson, G. \& Downe, S. (2013). A hero's tale of childbirth. Midwifery 29(7), 76571. DOI: 10.1016/j.midw.2012.07.008.

Westphal, M., \& Bonanno, G.A. (2007). Posttraumatic growth and resilience to trauma: different sides of the same coin or different sides. Applied Psychology: An International Review, 56, 417-427. DOI: 10.1111/j.1464-0597.2007.00298.x

White, G. (2007). You cope by breaking down in private: fathers and PTSD following childbirth. British Journal of Midwifery, 15(1), 39-45.

DOI: http://dx.doi.org/10.12968/bjom.2007.15.1.22679

White, T., Matthey, S., Boyd, K., \& Barnett, B. (2006). Postnatal depression and post-traumatic stress after childbirth: Prevalence, course and co-occurrence. Journal of Reproductive and Infant Psychology, 24(2); 107-120.

DOI: $10.1080 / 02646830600643874$

World Health Organisation. (1992). ICD-10 Classifications of Mental and Behavioural Disorder: Clinical Descriptions and Diagnostic Guidelines. Geneva: World Health Organisation.

Yonkers, K.A., Smith, M.V., Forray, A., Epperson, C,N., Costello, D., Lin, H., \& Belanger, K. (2014). Pregnant women with posttraumatic stress disorder and risk of preterm birth. JAMA Psychiatry. DOI: 10.1001/jamapsychiatry.2014.558. [Epub ahead of print]

Zeitlin, J., Szamotulska, K., Drewniak, N., Mohangoo, A.D., Chalmers, J. ... \& The Euro-Peristat Preterm Study Group. (2013). Preterm birth time trends in Europe: a study of 19 countries. BJOG: An International Journal of Obstetrics and Gynaecology, 120, 1356-1365. DOI: 10.1111/1471-0528.12281 


\section{Appendix 1: participants}

Susan Ayers
Ros Crawley
Elizabeth Ford

Antje Horsch

Jane lles

Julie Jomeen

Kirstie McKenzie-McHarg

Aimee Poote

Alexandra Sawyer

Geraldine Scott-Heyes

Kayleigh Sheen

Pauline Slade

Claire Stramrood

Gill Thomson 